\title{
On Investment Risk Control of Financial Derivatives
}

\author{
Wang Yajing \\ Shandong University(Weihai) \\ hunter2011@foxmail.com
}

Keywords: Risk analysis of financial derivatives risk control

\begin{abstract}
The emergence and rapid development of derivative financial instruments makes a huge impact on the current accounting system lying in accrual basis and accounting model of historical cost measurement principle, which make it more difficult for the risk management. This paper first describes the risk types of derivative financial instruments and on this basis, further studies of enterprise financial derivatives investment risk control measures and process supervision come to a corresponding solution so as to help companies effectively avoid the risk of financial derivatives investment.
\end{abstract}

\section{Risk types of financial derivatives investment}

Law Risk. Law risk refers to the financial loss due to the continuous financial innovation, which makes it difficult to guarantee the legitimacy of some derivative financial instruments. As the derivative financial instruments are in constant innovation, the regulatory agency and the enterprise, exchange, brokerage firm and other enterprises engaged in derivative financial instruments can produce asymmetric information, and sometimes they are not able to follow the risk in the dispute. From the point of view of law risk, OTC risk is particularly prominent.

Institutional Risk. It is also known as "system risk" which refers to a company or local market turbulence, causing other companies or the entire market to suffer from a common risk. The system risk is likely to trigger a series of system crisis, and even seriously damage the entire financial system. It reflects the fragility of the financial system to the turbulence. Because of the higher concentration, some of the trading strategies of derivative financial instruments, which may increase the volatility of the underlying market, the existence of poor information disclosure etc. The derivative financial instruments may lead to market system risk. Therefore, the institutional risk of derivative financial instruments is very subtle and more destructive.

Market Risk. Market risk is also referred to as price risk, which is the uncertainty of the price fluctuation of derivative financial instruments. The main factors occur: the underlying asset price volatility, and the purpose and means of derivative financial instruments, derivative financial instruments sorts, leverage nature of derivative financial instruments.

Credit Risks. Credit risk, also known as the breach risk, refers to the risk caused by the breach of a party in a derivative financial instrument. Credit risk refers to the risk that the counterparty risk is the possibility that the other party may fail to fulfill the contract and cause the loss to the other party.

Operational Risk. Operational risk refers to the risk of the failure of the internal control system in the process of trading and settlement, due to the imperfections of the internal control system and the occasional failure of the computer network system. Operational risk can be divided into two categories, the first category is due to the imperfect internal supervision system, management loopholes, the work flow is not reasonable, so that the transaction decision makes risk due to human or non-human error. The other category refers to the possibility of making loss for derivative financial instrument dealers, due to a variety of occasional accidents or natural disasters, such as computer system breakdowns, communication system paralysis, earthquake, fire disaster, mistakes by workers.

Liquidity Risk. In the course of the performance of the contract, the risk of financial assets can not be sold at the price that is close to the fair value because of the difficulty in financing. Liquidity risk depends on the degree of standardization of the contract, the market trading rules and the 
change of market environment. In the OTC derivative financial instruments, there is no fixed format for each contract lacking the circulating parallel market, so the liquidity risk is bigger. Liquidity risk has an important impact on the cash flow of the enterprise, which may cause the enterprise to have a financial crisis due to a temporary capital turnover, the serious problems may cause the enterprise to close down.

Settlement Risk. Settlement risks contain two aspects. The first is the risk made by payment time differences. The other risk is the clearing loss caused by waving derivative financial instruments. When the sort is getting close to delivery, parts of dealers behave deliberately illegal, which will make the price of the treasury bonds and futures sharply changed.

\section{Financial derivatives investment control measures}

Gradually improve the ability to avoid risks. The first is to cultivate the specialized personnel of financial derivative products, the specialized research institutions of the development of the financial derivatives. The second is to strengthen the financial derivatives market related legislation, to improve the rules and regulations, in the national macro-control and guide the gradual development so as to avoid blind investment to the country and investors to bring risks and losses. The third is to actively develop the entrusted financial derivatives transactions and establish intermediary financial institutions or non-financial institutions that carry excellent investment and risk mechanisms. Thus, financial derivative implement market need to be gradually developed by investing instead of clients or making deals. The fourth is to push forward the reform of state-owned enterprises, continue to deepen the reform of financial, taxation, investment and financing systems, strengthen effective supervision, and establish a market economic and legal supervision system, from the system and management to provide a broad development space and orderly circulation environment.

Revise the Definition of Accounting Elements. Financial Accounting Standards Board the 133rd version issued by the United States financial accounting standards board FASB1998 in June" derivative and hedging activities of accounting" raised a new idea to this issue. Its emphasis on the critical point of the definition of assets and liabilities is some future economic interest or loss exists in assets and liabilities. And derivative financial instruments in this important aspect is in line with the definition of assets and liabilities, therefore it should be reflected in the report as assets or liabilities. And IASC presents the concept of financial assets and financial liabilities: financial assets include cash; from another business to receive cash or another financial assets of the contractual rights; in the potential favorable conditions, with another business exchange of financial instruments of the contract rights; the other is the interests of enterprises. Financial liabilities include the delivery of cash or another financial asset to another enterprise; the exchange of financial instruments with another enterprise under potentially adverse conditions. Although FASB's new interpretation of the financial instruments of the people of the assets and liabilities of the ranks, but can not fundamentally change the fact that it does not meet the definition of accounting elements. So I think it is necessary to expand the connotation and extension of the current financial statement elements, and should not be limited to "past" and should emphasize "the economic benefits and the need to be borne by the enterprises in the future.

Reestablish of Accounting Confirmation Standards. The international accounting standards board IASC has set up two criteria: one is that all substantial risks and rewards related to assets or liabilities have been transferred to the enterprise: the other is the cost of the assets acquired by the enterprise and the fair market price or the amount of debt that must be reliably measured. Such recognition criteria do not have to be based on the occurrence of transactions or events, but in the event that the enterprise is a party to the contract, the risk and remuneration of the relevant risks and whether the occurrence of a substantial transfer is the so-called "risk and remuneration act"'". There is no dispute in the initial confirmation, but there is a problem when it is terminated. Because of the variety of derivative financial instruments, not all can be easily judged at the time of the contract and the risk of payment and the transfer of substantive, there is only part of the transfer. To this end, financial instruments of the steering committee of the CICA proposes the financial synthesis, the 
method pointed out that when an enterprise to achieve various powers stated in the contract, or when enterprises give up or lose their financial assets contract control, you should confirm the termination of a financial asset. At the end of thirty-ninth, the "international accounting standards" (IASC39) 1998 "financial instruments: recognition and measurement" and further provides that enterprises in the contracting parties, regardless of what financial instruments involved, must be recognized financial assets or financial liabilities. For the assets or liabilities that have been recognized, from the past to the future trading of this period of time, although the risks and rewards are established and no substantial change, but due to the exchange rate, price and other factors will cause changes in fair value, and thus need to be confirmed. According to FASB's 133 point of view, this part of the value of the increase or decrease can not be treated as assets or liabilities. But as long as the amount of the change can be measured reliably, it should be based on the specific circumstances, respectively, to confirm the profit for the period of change. This is clearly inconsistent with the establishment of the principle of recognition of the statement on the basis of the transaction has been realized. The gains and losses of recognition are not realized in itself, but the change in the external factors is not the real cause. But in this way, we can reveal the risk and benefit of the derivative financial instruments to the enterprise, and make it more conducive to the implementation of dynamic risk management.

Re-choosing Accounting Measurement Attributes. Because the derivative financial instruments only produce the contractual rights and obligations, and the transaction and the event did not really happen, therefore, there is no historical cost. But at this time, the return and risk of the two sides have already begun to shift. Confirmation and measures have been put onto the accounting. In this regard, IASC is divided into three categories according to the purpose of enterprise management, and the financial tools are divided into three categories. The first is that if the enterprise intends to hold it in long-term or hold it to deadline, the historical cost measurement is made. Secondly, if enterprises hold financial instruments for the purpose of keep the value of assets or debt, calculating will be figured in accordance with the schedule fair value or current market price. Thirdly, other financial tools figure out the income or loss into current earnings as the schedule fair value or current market price changes.

Re-improve the Disclosure Ways of Accounting Information. According to the disclosure of derivative financial instruments, including the terms of the nature of the derivative financial instruments, including the value of the derivative financial instruments, including the value of the derivative financial instruments, including the value of the derivative financial instruments, including the value of the derivative financial instruments, including the value of the derivative financial instruments, including the value of the derivative financial instruments, including the value of the derivative financial instruments, the two is the fair value of the derivative financial instruments. Additional disclosure, such as the disclosure of the financial assets and liabilities related to the loss and change of the financial assets and liabilities related to the disclosure of financial assets and liabilities, the use of derivative financial instruments for business purposes and the management of its risk control policies, etc..

\section{Strengthening the Risk Control Process of Financial Derivatives Investment}

Make clear management strategies on risk system. In the development of a company, we need to define what kind of derivative risk that an enterprise can bear, what risk can not be burdened, and the maximum risk value that an enterprise can bear. Limit management are carried out onto the financial derivatives business and strengthen capital risk awareness. Further analysis and research should be proceeded for concrete business style and product varieties of new available derivative business.

Make clear risk monitoring business processes. Risk monitoring business process includes the following five procedures: firstly, identify the risk. The financial institution should be in accordance with the business objectives, capital strength, management ability and risk characteristics of derivatives, and determine the suitable varieties and scale of derivatives. Secondly, risk assessment must be independent from the third parties to transaction varieties. The counterparty makes credit 
risk analysis and evaluation and carefully selects the appropriate risk assessment model and monitoring system. Thirdly, standardize the operation procedure of the financial derivative instruments, which should cover all the key links in the prior prevention, monitoring and post processing. Fourthly, operational risk should be qualified and controlled by setting up a standardized licensing examination and approval system. A clear authorized procedure should be worked out. Fifthly, financial risk assessment on derivatives business is in need. It is also necessary that regular supervision and inspection on the normative and effective internal control system of enterprise financial derivatives.

Improve risk monitoring technology facilities construction. Improve the risk assessment system of derivative instruments by completing the construction of risk information transmission system, pre-warning model and early warning index system, establishment of the corresponding measurement evaluation model and establishment of enterprise financial derivatives business risk reporting system,

Improve the risk management system before and after the transaction. Formulate the policies and procedures of the risk management of financial derivatives, and to define the policy of risk management. Enterprises can establish a financial derivative risk early warning system through field visits, email, fax, telephone recording, etc., and establish the risk early warning system of financial derivatives.

Set up a post-crisis rescue plan system. In the financial derivative market, even if the derivative business organization itself is good, the credit risk caused by accidental events may also endanger the company. The establishment of the system of crisis rescue plan, on the one hand, it is conducive to increase the mutual trust between the traders, reduce the occurrence of moral hazard. On the other hand, it can take remedial measures immediately after the occurrence of the transaction risk, to prevent further expansion of the loss. Therefore, the results of the internal valuation of the company to check with the counterparty, such as significant differences to immediately identify the causes and take effective measures. If the market is a major change or a major loss, it is necessary to set up a special working group and actively respond to properly handle.

\section{Conclusion}

In recent years, with the rapid development of the financial industry, the derivative financial instruments have been widely used. On the one hand, enterprises and financial institutions through the use of derivative financial instruments to avoid the risk; on the other hand, derived financial instruments of leverage, volatility characteristics determine its considerable risk, many investors under the temptation of interests tend to ignore of derivative financial instruments trading risks, and bring huge economic losses to the enterprise. All kinds of crises caused by the derivative financial instruments have made people start to review its function, and it is necessary to reduce the risk of derivative financial instruments to make full use of the positive effect of derivative financial instruments. Therefore, we should always pay attention to the high risk of the derivative financial instruments and the efficiency of the investment.

\section{References}

[1] B.Q. He. Comparing Analysis of Chinese and Foreign Financial Derivative Tools----Take the examples of Interest Futures and Interest Option[J].Modern Economic Information.2012(21)

[2] F.Q. Yue. Analysis on Investment Risk and Avoidance Strategies of Financial Derivative Tools.Chinese Stock and Futures. 2011(06)

[3] T. Liang. Thoughts on Risk Supervision of Financial Derivative Tool Deals . Southern Finance. 2010(08)

[4] C.H. Dun. Risk Management Studies of Financial Derivative Tool Risk . Financial News. 2010(17)

[5] J. Chu. Analysis on Financial Derivative Tool Risk and Management. Finance in Zhejiang Province.2010(02). 